\title{
Overwintering, Cold Tolerance and Supercooling Capacity Comparison Between Liriomyza Sativae and $L$. Trifolii, Two Successively Invaded Leafminers in China
}

Qikai Zhang

Chinese Academy of Agricultural Sciences

Shengyong Wu

Chinese Academy of Agricultural Sciences

Haihong Wang

Chinese Academy of Agricultural Sciences

Zhonglong Xing ( $\square$ longtaitou100@126.com)

Chinese Academy of Agricultural Sciences

Zhongren Lei

Chinese Academy of Agricultural Sciences

\section{Research Article}

Keywords: Liriomyza trifolii, Liriomyza sativae, overwintering, cold tolerance, distribution pattern, species displacement

Posted Date: June 15th, 2021

DOI: https://doi.org/10.21203/rs.3.rs-581073/v1

License: (c) (i) This work is licensed under a Creative Commons Attribution 4.0 International License.

Read Full License

Version of Record: A version of this preprint was published at Journal of Pest Science on August 12th, 2021. See the published version at https://doi.org/10.1007/s10340-021-01420-0. 


\section{Abstract}

Liriomyza sativae Blanchard and Liriomyza trifolii (Burgess) are two highly polyphagous pests that successively invaded China in the 1990s and 2000s, respectively, threatening vegetable and horticultural plants. Competitive displacement of $L$. sativae by $L$. trifolii occurred during the expansion process of the latter in southern China. However, whether L. trifolii can expand their range to northern China and, if so, how they compete with $L$. sativae in northern China remains unclear. Overwintering and cold tolerance capacity largely determine the species distribution range and can affect species displacement through overwintering and phenology. In this study, we compared the overwintering potential, cold tolerance and supercooling point (SCP) between these two leafminer species. Our results showed that $L$. trifolii can overwinter at higher altitudes than L. sativae. In addition, we found that they can both successfully overwinter in greenhouses in northern China, and the overwintering capacity of L. trifolii was higher than that of $L$. sativae. Moreover, the extreme low-temperature survival of $L$. trifolii was significantly higher than that of L. sativae, and the SCP of the former was lower than that of the latter. We thus conclude that the overwintering and cold tolerance capacity of $L$. trifolii is much better than that of L. sativae. Our findings indicate that $L$. trifolii has the potential to displace $L$. sativae and expand its range to northern China. Moreover, our results have important implications for predicting overwinter ranges and developing management strategies for invasive leafminers in China.

\section{Key Message:}

- Overwintering experiments at 16 locations spanning 7 degrees of latitude in China showed that the overwinter boundaries of $L$. trifolii and $L$. sativae were $36.4^{\circ}$ and $35.4^{\circ} \mathrm{N}$, respectively.

- Overwintering capacity of $L$. trifolii was higher than that of $L$. sativae under greenhouse and field conditions in northern China.

- The extreme low-temperature survival of L. trfolii was higher than that of L. sativae at zero and subzero temperatures under different exposure times.

- The supercooling point of $L$. trfolii $\left(-22.56^{\circ} \mathrm{C}\right)$ was lower than that of $L$. sativae $\left(-11.79^{\circ} \mathrm{C}\right)$.

- These overwintering and cold tolerance advantages of $L$. trifolii would contribute to their range expanding and enhance their competitive displacement over $L$. sativae.

\section{Introduction}

L. sativae and $L$. trifolii are among the most economically important leafminers damaging a wide range of vegetable and ornamental plants (Kang et al. 2009). They both originated on American continents and have become cosmopolitan pests due to international global trade since the 1960s (Gao et al. 2017a). In China, L. sativae was first detected on Hainan Island in 1994, and L. trifolii was first detected in Guangdong Province in 2005 (Wen et al. 1996; Lei et al. 2007). L. sativae and L. trifolii are two very closely related species that have similar morphology and can even have hybrid offspring (Sakamaki et al. 2005; Tokumaru and Abe 2005). In addition, their host plant ranges are similar, and they share similar 
ecological niches in the same host plant (Xing et al. 2017). Therefore, the invasion and expansion of $L$. trifolii would encounter and compete with $L$. sativae. Previous studies showed that $L$. trifolii gradually displaced the previously dominant L. sativae when they invaded Hainan and Guangdong Provinces (Gao et al. 2014). However, whether L. trifolii can overcome L. sativae and expand its distribution to higher altitudes in northern China has still not been studied.

Climatic tolerances, including thermal tolerances, largely determine species ranges and can affect competitive displacement among insects (Kang et al. 2009; Reize and Trumble 2002). In addition, interacting species often differ in their thermal tolerances; for instance, a higher extreme high-temperature tolerance of L. trifolii over L. sativae was found in laboratory populations (Wang et al. 2014). In addition, the prerequisite for insects to establish in a new area is that adequate individuals can survive in lowtemperature winter periods (Bale 1996; Huang et al. 2020; Li et al. 2020). Therefore, the low temperatures during winter in newly invaded areas were assumed to be able to prevent the establishment of invasive species (Kahrer et al. 2019). Consequently, low-temperature survival and overwintering ability largely determine the geographical distribution of invasive species. Low-temperature adaptability can also affect competitive displacement between invasive and local insect species through temporal and phenological differences (Gao et al. 2017b).

L. sativae and L. huidobrensis, which both invaded China in the 1990s, were found to be largely differed in their cold tolerances, which thus resulted in their specific geographic and overwinter ranges (Kang et al. 2009). They can survive above $0^{\circ} \mathrm{C}$ for long-term exposure but can survive for several minutes to several days below $0^{\circ} \mathrm{C}$, and the low-temperature survival of L. sativae is lower than that of L. huidobrensis (Chen and Kang 2002; Chen and Kang 2005). Moreover, the supercooling point (SCP) of L. huidobrensis was significantly lower than that of L. sativae (Chen and Kang 2004; Chen and Kang 2005). Consequently, the distinct range distributions of $L$. sativae and $L$. huidobrensis were formed during their invasion and expansion in China (Kang et al. 2009). L. trifolii emerged and damaged earlier than L. sativae in the upcoming year after winter (Chang et al. 2016). However, no research was available for their cold tolerance and overwinter abilities, given the more drastic competitive interactions between $L$. trifolii and $L$. sativae in China, Japan and the United States (Gao et al. 2011; Abe 2017).

We want to address two questions in this study: (1) Does the latter invasive $L$. trifolii have overwintering advantages over the previously invasive $L$. sativae? (2) What is the cold tolerance mechanism underlying their overwintering differences? We used $L$. sativae and $L$. trifolii pupae to answer these questions because they usually overwinter in the puparial stage (Parrella 1987). To examine their overwinter potentials, we first conducted overwinter experiments at 16 local sites along latitude gradients. The greenhouse and field overwinter potentials of $L$. sativae and $L$. trifolii were also compared in northern China. To compare their cold tolerances, their survival rates under different extremely low temperatures $(5$, $0,-10,-20^{\circ} \mathrm{C}$ ) at different exposure durations were estimated in the laboratory. In addition, the SCP of $L$. sativae and $L$. trifolii was determined.

\section{Materials And Methods}




\subsection{Insect rearing and pupae preparation}

Populations of $L$. trifolii and $L$. sativae were collected from field vegetable plants in Sanya, Hainan Province, China $\left(18^{\circ} 14^{\prime} 52^{\prime \prime} \mathrm{N} ; 109^{\circ} 30^{\prime} 29^{\prime \prime} \mathrm{E}\right)$. They were subsequently cultured on kidney bean plants (Phaseolus vulgaris L.) at $26 \pm 1^{\circ} \mathrm{C}$, humidity at $75 \%$ with a $14: 10$ light: dark photoperiod. The two species were reared for more than 3 generations to ensure the homogeneity of each population before the two species were used in the experiments.

We used pupae to investigate the overwinter potential and cold tolerance of these two leafminer species. One-day-old pupae were used in the following experiments because this stage was developmentally mature and most sensitive to thermal stress (Parrella 1987; Zhao and Kang 2000).

\subsection{Overwintering capacity along latitudinal gradients}

To determine the overwintering capacity and overwintering boundary of the two leafminer species in China, we conducted overwintering experiments from November 2019 to April 2020 at 16 locations spanning 7 degrees of latitude from $30.23^{\circ}$ to $37.43^{\circ} \mathrm{N}$ in Central and North China (Fig. 1). We used a specialized bottle (Fig. 2) to perform the overwintering experiments: we put the bottles into the topsoil (Fig. 2) of each location (Linden 1993). Each bottle contained 100 pupae and was treated as one replicate. Each location was replicated 5 times. We started the experiments in the northernmost location (Hebei Province) in early November 2019 and ended in the southernmost location (Zhejiang Province) in late November 2019. In April 2020, we collected pupae from north to south and placed them into a climate chamber at $26 \pm 1^{\circ} \mathrm{C}$ and humidity: $75 \%$ with a $14: 10$ light: dark photoperiod. We checked the survival rate of each replicate.

\subsection{Overwintering capacity in common garden experiments}

To compare the overwintering ability of the two species in northern China, we carried out common garden experiments under greenhouse and field conditions at the Langfang Experimental Station, Institute of Plant Protection (IPP), Chinese Academy of Agricultural Science (CAAS) $\left(39^{\circ} 30^{\prime} 38^{\prime \prime} \mathrm{N} ; 116^{\circ} 36^{\prime} 2^{\prime \prime} \mathrm{E}\right)$. We put bottles (Fig. 2) into the topsoil of experimental fields and greenhouses (Linden 1993). Each bottle contained 100 pupae and was treated as one replicate. We started the experiments at late December 2019. We collected the pupae of each replicate in fields and greenhouses every 10 days, and we ended the experiments after 100 days of exposure (early April 2020). Survival rate of each sampling was checked in laboratory. The combination of each species and duration of exposure was considered one treatment. Each treatment was replicated 5 times.

\subsection{Cold tolerance capacity}

To determine the cold tolerance capacities of the two leafminer species, their pupae were exposed to $5^{\circ} \mathrm{C}$ and $0^{\circ} \mathrm{C}$ for $1,2,3,4,5$ and 6 days and exposed to $-10^{\circ} \mathrm{C}$ and $-20^{\circ} \mathrm{C}$ for $10,20,30,40,50$ and 60 minutes. We considered the combination of each temperature and duration of exposure as one treatment. There 
were 5 replicates of each treatment, and each replicate contained 100 pupae. We checked the survival rate of each treatment under laboratory conditions.

\subsection{Supercooling point determination}

The supercooling points (SCPs) of the pupae of the two leafminer species were determined following the method described by Zhao and Kang (2000). We used a thermocouple (Testo, model 177-T4, Germany) to determine their SCPs. The individuals of the two species were fixed to the end of the sensor (nickel-worm) of the thermocouple by white petrolatum. Individuals were cooled at a rate of $0.5^{\circ} \mathrm{C}$ per minute in a programmable refrigerated test chamber. Any decrease in the temperature was recorded. The SCPs were defined as the lowest temperature before an exothermic reaction, as indicated by a sudden temperature increase. Each species was tested for 50 pupae. The SCP data were read using Comsoft3 Software.

\subsection{Statistical analysis}

We fitted a linear mixed model (LMM) with the Ime function from the Ime4 package (Bates et al. 2015) to compare the survival rate of overwintering pupae in the field and common garden experiments. To evaluate the overwintering capacity along latitudinal gradients, we fitted a linear mixed model with the survival rate as the response variable, species and region as fixed factors, and latitude as a random factor. To evaluate the overwintering capacity in the common garden experiments, we fitted linear mixed models with the survival rate as the response variable, species as a fixed factor, and duration of exposure as a random factor. In addition, we fitted linear models with the survival rate as the response variable and latitude as the explanatory variable.

To evaluate their cold tolerance capacities, we fitted linear mixed models with the survival rate as the response variable, species as a fixed factor, and duration of exposure as a random factor. All linear mixed model results were summarized with ANOVA. The SCP data were read using Comsoft3 Software. The independent-sample Student's $t$-test was used for comparison of SCPs and for comparison of the survival rate of each experiment between $L$. trifolii and L. sativae.

All statistical analyses were conducted using R (version 3.6.3). We performed a normality test and residual test for all linear mixed models in R (package 'DHARMa', Hartig 2019). The results showed that all the data met the conditions for fitting the models. We also checked the SCP data for normality and equality of variances prior to statistical analysis.

\section{Results}

\subsection{Overwintering capacity along latitudinal gradients}

The overwintering survival of $L$. trifolii pupae was significantly higher than that of $L$. sativae pupae ( $F=$ $51.704, P<0.001$; Fig. 3a). However, the $L$. trifolii pupae showed the same types of latitudinal patterns between ranges, as their overwintering survival decreased linearly with increasing latitude (L. trifolii: 
survival rate $=-5.98+220.61 *$ lat, $R^{2}=0.7453 ;$ L. sativae: survival rate $=-4.15+150.70 *$ lat, $R^{2}=0.7323$ ) (Fig. 3b). L. trifolii pupae successfully overwintered at $36.4^{\circ} \mathrm{N}$, while L. sativae pupae successfully overwintered at $35.4^{\circ} \mathrm{N}$ (Fig. 3b).

\subsection{Overwintering potential in common garden experiments}

In the field, we found that the pupae of both L. trifolii and L. sativae did not successfully overwinter, but they showed different survival rates for different exposure durations $(F=16.101, P<0.001)$. The survival rate of $L$. trifolii pupae was significantly higher than that of $L$. sativae pupae when the exposure durations were $30,40,50$ and 60 days (Fig. 4a).

In the greenhouse, we found that the pupae of both L. trifolii and L. sativae could successfully overwinter; however, the overwintering survival of $L$. trifolii pupae was significantly higher than that of $L$. sativae pupae $(F=342.14, P<0.001)$. The survival rate of $L$. trifolii pupae was significantly higher than that of $L$. sativae pupae when the exposure durations were 20, 30, 40, 50, 60, 70, 80, 90 and 100 days (Fig. 4b).

\subsection{Cold tolerance capacity}

Extreme low-temperature survival results showed that when exposed to $5^{\circ} \mathrm{C}$ for different durations, no significant differences were found between the survival rates of $L$. trfolii pupae and $L$. sativae pupae ( $F=$ $0.1339, P=0.7083$; Fig. 5a). However, when they were exposed to $0,-10$ and $-20^{\circ} \mathrm{C}$, the survival rate of $L$. trifolii pupae was significantly higher than that of $L$. sativae pupae at different exposure durations $\left(0^{\circ} \mathrm{C}: F\right.$ $\left.=177.82, P<0.001 ;-10^{\circ} \mathrm{C}: F=87.5, P<0.001 ;-20^{\circ} \mathrm{C}: F=69.646, P<0.001\right) . L$. sativae pupae did not survive when they were exposed to $0^{\circ} \mathrm{C}$ for more than 4 days, while $L$. trifolii pupae survived at $0^{\circ} \mathrm{C}$ for more than 6 days (Fig. $5 b$ ). The survival rate of L. trifolii pupae was significantly higher than that of $L$. sativae pupae when the exposure duration was more than 30 minutes at $-10^{\circ} \mathrm{C}$ (Fig. $5 \mathrm{C}$ ). L. trifolii pupae can survive at $-20^{\circ} \mathrm{C}$ for more than 40 minutes, while for $L$. sativae pupae, the survival rate is lower than $10 \%$ when exposed to $-20^{\circ} \mathrm{C}$ for 30 minutes (Fig. $5 \mathrm{~d}$ ).

\subsection{Supercooling point}

The SCP of $L$. trifolii was significantly lower than that of $L$. sativae $(t=32.172, P<0.001$; Fig. 6$)$. The mean SCP of $L$. trifolii was $-22.56 \pm 0.24^{\circ} \mathrm{C}$ (ranging from -17.10 to $-25.16^{\circ} \mathrm{C}$ ). The mean SCP of L. sativae was $-11.79 \pm 0.22^{\circ} \mathrm{C}$ (ranging from -9.20 to $-18.09^{\circ} \mathrm{C}$ ).

\section{Discussion}

Climatic stresses, including overwintering and cold tolerance capacity, largely determine the species distribution of leafminers (Chen and Kang 2005; Kang et al. 2009). L. sative and L. trifolii are two devastating leafminers that invaded China in the 1990s and 2000s, respectively (Gao et al. 2015; Xing et al. 2017). L. sativae are now distributed in most provinces of China, while L. trifolii is found in only 10 provinces (Gao et al. 2017a). However, in contrast to their distribution ranges, we found that the 
overwintering potential and cold tolerance capacities of $L$. trifolii were both higher than those of $L$. savivae.

L. trifolii was reported to be able to overwinter safely in the field of Maryland $\left(39^{\circ} \mathrm{N}\right)$, United States (Larew et al. 1986); however, we found here that only $2 \%$ L. trifolii pupae can successfully overwinter at $36.4^{\circ} \mathrm{N}$ in China. For L. sativae, it was proposed that they could not overwinter outside as far north as latitude $34^{\circ} \mathrm{N}$ in China (Zhao and Kang 2000). Here, we found that $2.4 \%$ of L. sativae pupae can successfully overwinter at $35.4^{\circ} \mathrm{N}$. Prior work has suggested that many species are likely to move poleward in latitude as warming starts (Jepsen, et al. 2008; Estay et al. 2009; Tingley et al. 2009). Thus, we speculated that a warming climate could improve the overwintering survival of $L$. sativae pupae. However, rapid cold hardening or cold acclimation during their invasion process from south to north may enhance their cold tolerance and move their overwintering boundary northwards (Chen and Kang 2005).

Although leafminers cannot overwinter in the fields of northern China, they may

overwinter in greenhouses that are widespread at higher latitudes (Chen and Kang 2005). We tested this hypothesis at Hebei, China $\left(39.5^{\circ} \mathrm{N}\right)$. Consistent with our expectation, the results showed that the two leafminers can both overwinter in the greenhouse at the experimental site, but they cannot overwinter in the field (Fig. 4). However, the survival rate of overwintering pupae of L. trifolii was significantly higher than that of $L$. sativae in the greenhouse, indicating that the former is more likely to become sources of overwintering leafminers in the upcoming year. This result was consistent with a previous report that $L$. trifolii emerged earlier than L. satiave in spring in Jiangsu Province, China (Chang et al. 2016).

Cold tolerance largely determines the overwintering capacities of leafminers (Chen and Kang 2005). Here, we found that the low-temperature tolerance of $L$. trifolii was higher than that of $L$. sativae (Fig. 5). Leafminers are freeze-susceptible or freeze-avoiding, and they can tolerate subzero temperatures by supercooling (Bale 1996; Chen and Kang 2002). In addition, the SCPs of leafminer pupae have been reported as an index of cold tolerance (Zhao and Kang 2000). Our results showed that the SCP of $L$. trifolii pupae $\left(-22.56^{\circ} \mathrm{C}\right)$ was significantly lower than that of $L$. sativae $\left(-11.79^{\circ} \mathrm{C}\right)$, indicating a lower crystallization temperature for $L$. trifolii pupae. The geographical distribution differences between leafminers were related to their distinct cold resistance abilities (Chen and Kang 2002; Kang et al. 2009). Accordingly, the higher cold tolerance abilities of $L$. trifolii over $L$. sativae would contribute advantages to the former in species abundance, distribution range and competitive interaction when they experienced low temperatures.

However, in contrast to the overwintering and cold tolerance advantages of $L$. trifolii, the distribution range of $L$. trifolii was obviously smaller than that of $L$. sativae according to our previous investigations (Gao et al. 2017). We considered that biotic resistance to species invasion and expansion could explain this contradictory phenomenon. The invasion and expansion of $L$. sativae occurred earlier than that of $L$. trifolii by more than 10 years (Gao et al. 2015). Given that L. sativae and L. trifolii share similar host plants and ecological niches (Xing et al. 2017), L. trfolii should compete and displace L. sativae during their invasion and expansion. Although $L$. trifolii has many competitive advantages over $L$. sativae, the 
displacement of $L$. sativae by $L$. trifolii was difficult and even reversed (Wang et al. 2014; Gao et al. 2015; Gao et al. 2017; Xing et al. 2017).

In conclusion, we compared the overwintering ability and cold tolerance of two successively invasive leafminers in China in this study. Our results suggested that the overwintering and cold tolerance capacities of $L$. trifolii were both higher than that of $L$. sativae, which implies that $L$. trifolii has the potential to displace $L$. sativae and colonize higher latitude regions in China. Thus, this study provides information for predicting the distribution patterns of the two widespread invasive leafminers in China. Moreover, knowledge of the cold hardiness and overwintering regions of $L$. trifolii and $L$. sativae can help develop management strategies for them. Future studies should clarify the discrepancy between their cold tolerance and current distribution pattern through common garden experiments and long-term field monitoring of their population dynamics.

\section{Declarations}

\section{Acknowledgments}

This work was supported by China Agriculture Research System of MOF and MARA, CARS-23-D-08; National Key Research \& Development (R\&D) Plan: 2017YFD0200900.

\section{Author contributions}

ZX and ZL designed the research. QZ and ZX conducted experiments. QZ, ZX and SW analyzed data. QZ and $Z X$ wrote the manuscript. All authors read and approved the manuscript.

\section{Competing interests}

There is no conflict of interests.

\section{References}

1. Abe Y (2017) Invasion of Japan by exotic leafminers Liriomyza spp. (Diptera: Agromyzidae) and its consequences. Appl Entomol Zoolog 52(2):175-182

2. Bale JS (1996) Insect cold hardiness: a matter of life and death. Eur J Entomol 93:369-382

3. Bates D (2014) Fitting linear mixed-effects models using the Ime4 Package in R

4. Chang Y, Shen Y, Dong C, Gong W, Tian Z (2016) Population dynamics of Liriomyza trifolii and Liriomyza sativae in Jiangsu. Chin J Appl Entomol 53(4):884-891

5. Chen B, Kang L (2002) Cold hardiness and supercooling capacity in the pea leafminer Liriomyza huidobrensis. Cryo-Lett 23(3):173-182

6. Chen B, Kang L (2004) Variation in cold hardiness of Liriomyza huidobrensis (Diptera: Agromyzidae) along latitudinal gradients. Environ Entomol 33(2):155-164 
7. Chen $B$, Kang $L$ (2005) Implication of pupal cold tolerance for the northern over-wintering range limit of the leafminer Liriomyza sativae (Diptera: Agromyzidae) in China. Appl Entomol Zoolog 40(3):437-446

8. Estay S, Lima M, Labra F (2009) Predicting insect pest status under climate change scenarios: combining experimental data and population dynamics modelling. J Appl Entomol 133(7):491-499

9. Gao Y, Lei Z, Abe Y, Reitz SR (2011) Species displacements are common to two invasive species of leafminer fly in China, Japan, and the United States. J Econ Entomol 104(6):1771-1773

10. Gao Y, Reitz SR, Xing Z, Ferguson S, Lei Z (2017a) A decade of leafminer invasion in China: lessons learned. Pest Manag Sci 73(9):1775-1779

11. Gao Y, Reitz SR (2017b) Emerging themes in our understanding of species displacements. Annu Rev Entomol 62:165-183

12. Gao Y, Reitz SR, Wei Q, Yu W, Zhang Z, Lei Z (2014) Local crop planting systems enhance insecticidemediated displacement of two invasive leafminer fly. PLoS One 9(3):e92625

13. Hartig F (2016) DHARMa: Residual diagnostics for hierarchical. Multi-Level / Mixed) Regression Models

14. Huang Y, Dong Y, Huang W, Ren B, Deng Q, Shi Y, Bai J, Ren Y, Geng Y, Ma H (2020) Overwintering distribution of Fall Armyworm (Spodoptera frugiperda) in Yunnan, China, and influencing environmental factors. Insects 11(11):805

15. Jepsen JU, Hagen SB, Ims RA, Yoccoz NG (2008) Climate change and outbreaks of the geometrids Operophtera brumata and Epirrita autumnata in subarctic birch forest: evidence of a recent outbreak range expansion. J Anim Ecol 77(2):257-264

16. Kahrer A, Moyses A, Hochfellner L, Tiefenbrunner W, Egartner A, Miglbauer T, Müllner K, Reinbacher L, Pilz C, Votzi J (2019) Modelling time-varying low-temperature-induced mortality rates for pupae of Tuta absoluta (Gelechiidae, Lepidoptera). J Appl Entomol 143(10):1143-1153

17. Kang L, Chen B, Wei JN, Liu TX (2009) Roles of thermal adaptation and chemical ecology in Liriomyza distribution and control. Annu Rev Entomol 54:127-145

18. Larew H, Knodel-Montz J, Poe S (1986) Liriomyza trifolii (Burgess)(Diptera: Agromyzidae) overwinters outdoors in Maryland. Proc. Entomol. Soc. Wash 88(1)

19. Lei Z, Zhu C, Zhang C (2007) Risk analysis of invasive Liriomyza trifolii (Burgess) in China. Plant Prot 033(001):37-41

20. Li XW, Li D, Zhang ZJ, Huang J, Zhang JM, Hafeez M, Wang LK, Guo WC, Lu YB (2020) Supercooling capacity and cold tolerance of the South American tomato pinworm, Tuta absoluta, a newly invaded pest in China. J Pest Sci 1-14

21. Linden A (1993) Overwintering of Liriomyza bryoniae and Liriomyza huidobrensis (Diptera: Agromyzidae) in the Netherlands. Proc Exper Appl Entomol (4): 145-150

22. Parrella MP (1987) Biology of Liriomyza. Annu Rev Entomol 32(1):201-224 
23. Reitz SR, Trumble JT (2002) Competitive displacement among insects and arachnids. Annu Rev Entomol 47(1):435-465

24. Sakamaki Y, Miura K, Chi Y (2005) Interspecific hybridization between Liriomyza trifolii and Liriomyza sativae. Ann Entomol Soc Am 98(4):470-474

25. Tingley MW, Monahan WB, Beissinger SR, Moritz C (2009) Birds track their Grinnellian niche through a century of climate change. Proc Natl Acad Sci 106(Supplement 2):19637-19643

26. Tokumaru S, Abe Y (2005) Interspecific hybridization between Liriomyza sativae Blanchard and $L$. trifolii (Burgess) (Diptera: Agromyzidae). Appl Entomol Zoolog 40(4): 551-555

27. Wang H, Reitz SR, Xiang J, Smagghe G, Lei Z (2014) Does temperature-mediated reproductive success drive the direction of species displacement in two invasive species of leafminer fly? PLoS One 9(6):e98761

28. Wen J, Wang Y, Lei Z (1996) New record of Liriomyza sativae Blanchard (Diptera Agromyzidae) in China. Entomotaxonomia 18:311-312

29. Xing Z, Zhang L, Wu S, Yi H, Gao Y, Lei Z (2017) Niche comparison among two invasive leafminer species and their parasitoid Opius biroi: implications for competitive displacement. Sci Rep 7(1):1-6

30. Zhao Y, Kang L (2000) Cold tolerance of the leafminer Liriomyza sativae (Dipt., Agromyzidae). J Appl Entomol 124(3-4):185-189

\section{Figures}




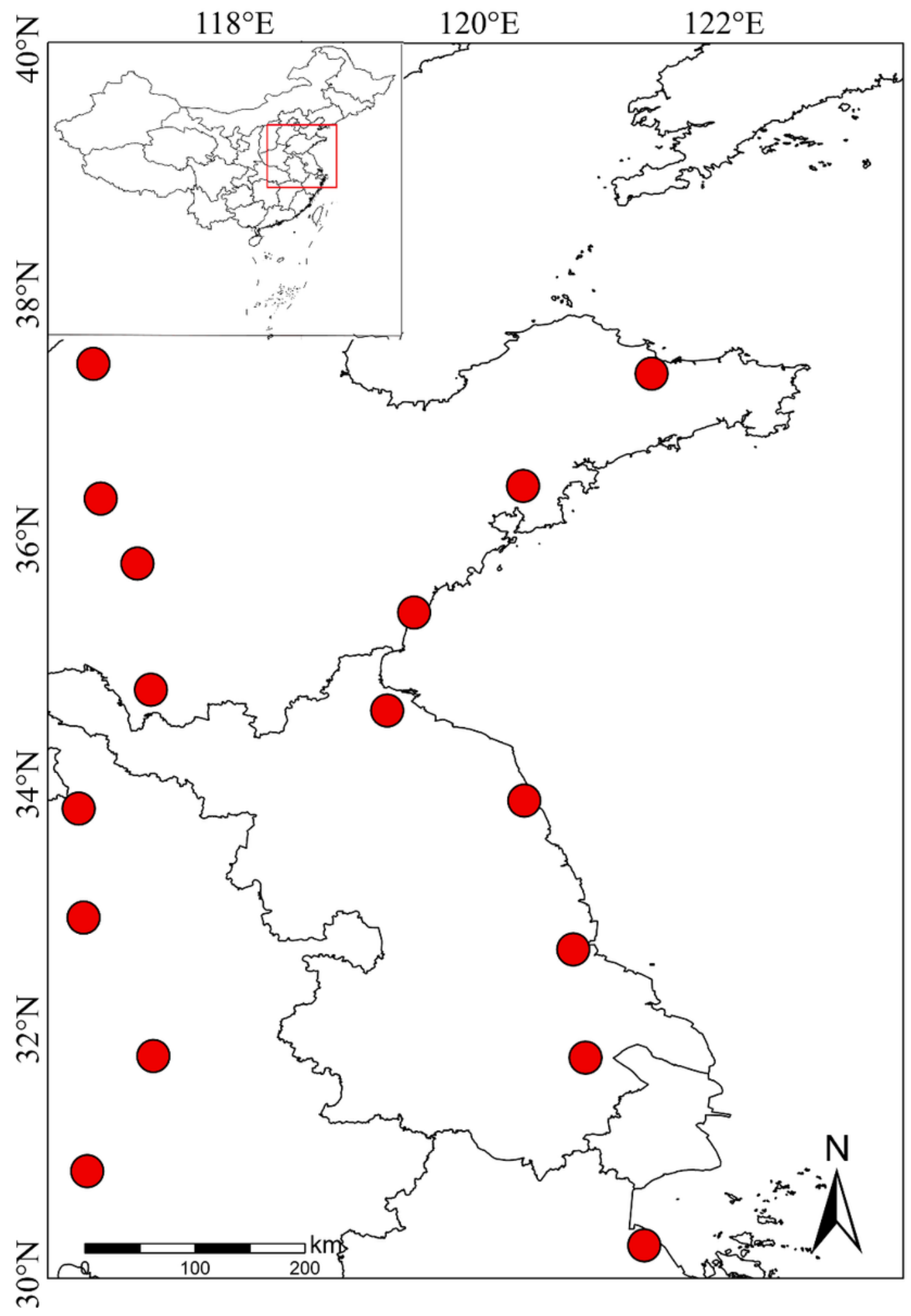

\section{Figure 1}

Locations of doing the overwintering experiment along latitude gradient. ArcView GIS (version 3.2) was used to produce a distribution map based on the geographical coordinates of the localities, which were obtained with a Global Positioning System receive. Note: The designations employed and the presentation of the material on this map do not imply the expression of any opinion whatsoever on the part of Research Square concerning the legal status of any country, territory, city or area or of its 
authorities, or concerning the delimitation of its frontiers or boundaries. This map has been provided by the authors.

\section{Aboveground}

\section{Belowground}

Holes

Topsoil

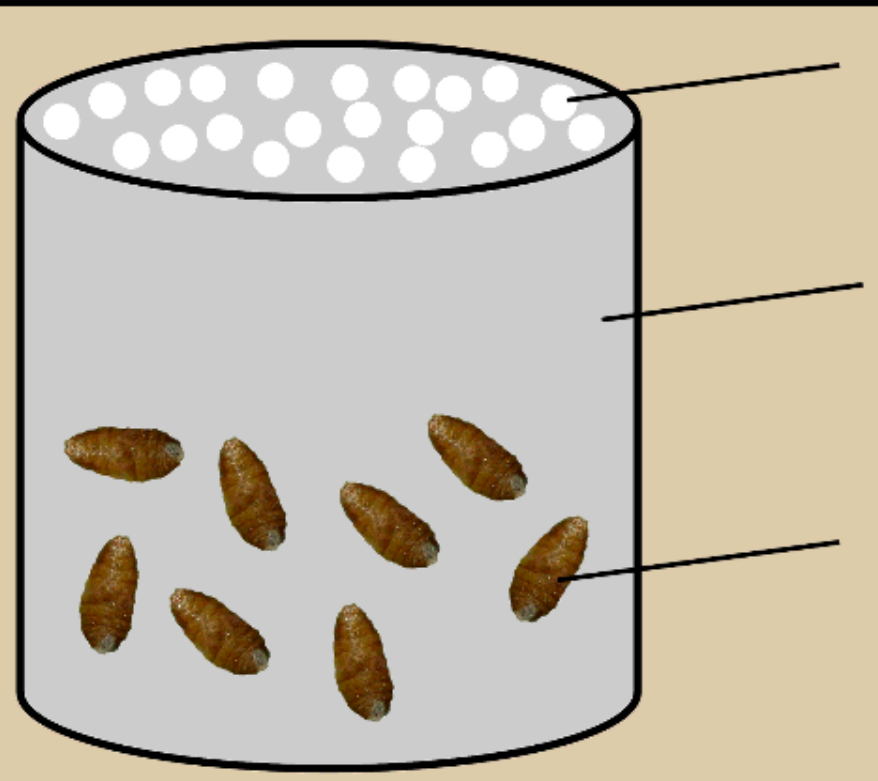

Glass bottle

Pupae

Figure 2

Schematic diagram of overwintering experiments
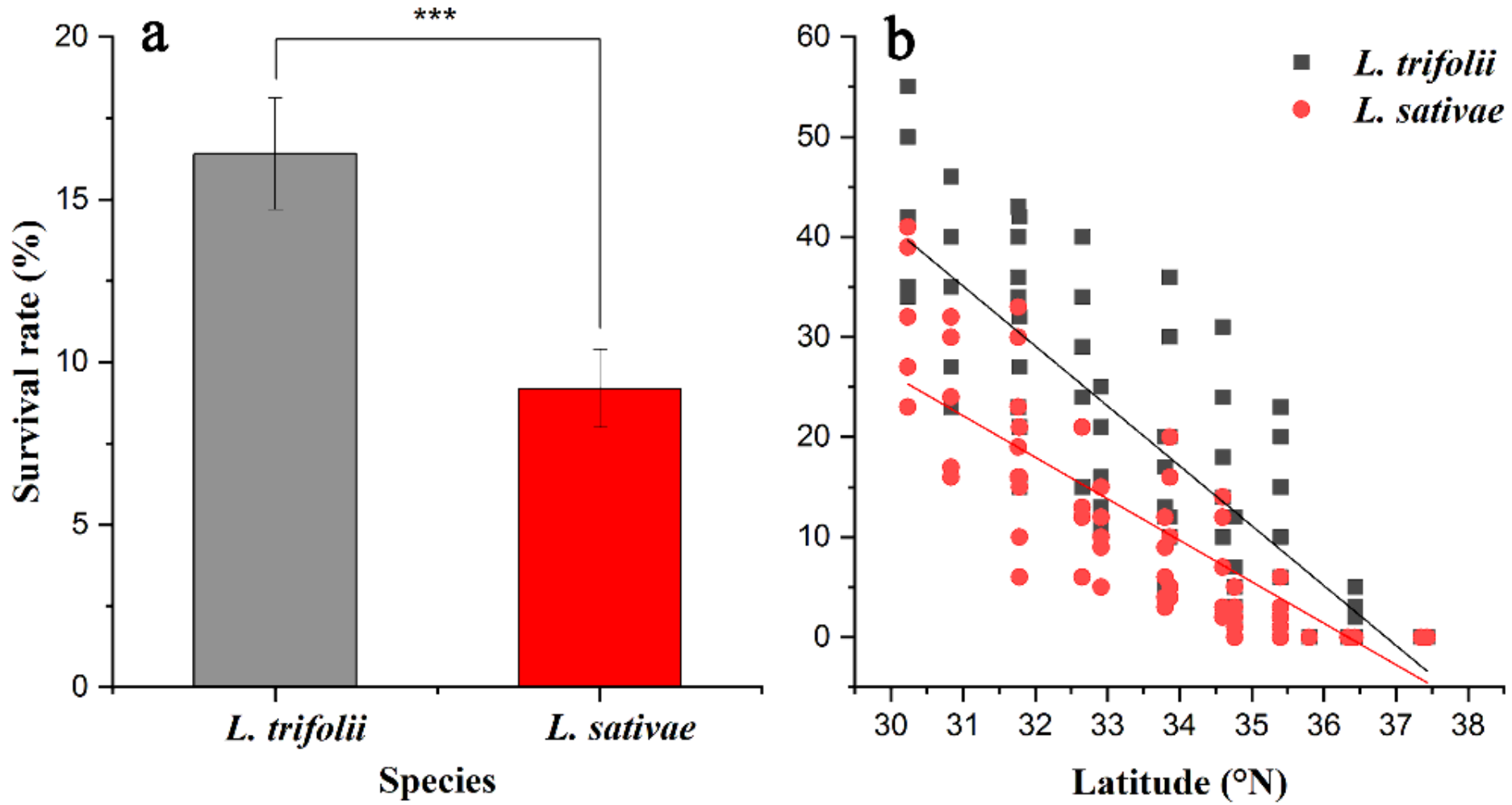
Figure 3

Survival rate of the overwintering pupae of L. trifolii (dark bar/square) and L. sativae (red bar/circle) with latitude. ${ }^{* \star *} P<0.001$. Bars indicate means \pm SEM in (a). The dark squares and red circles in (b) indicate the survival rates of $L$. trifolii and L. sativae, respectively

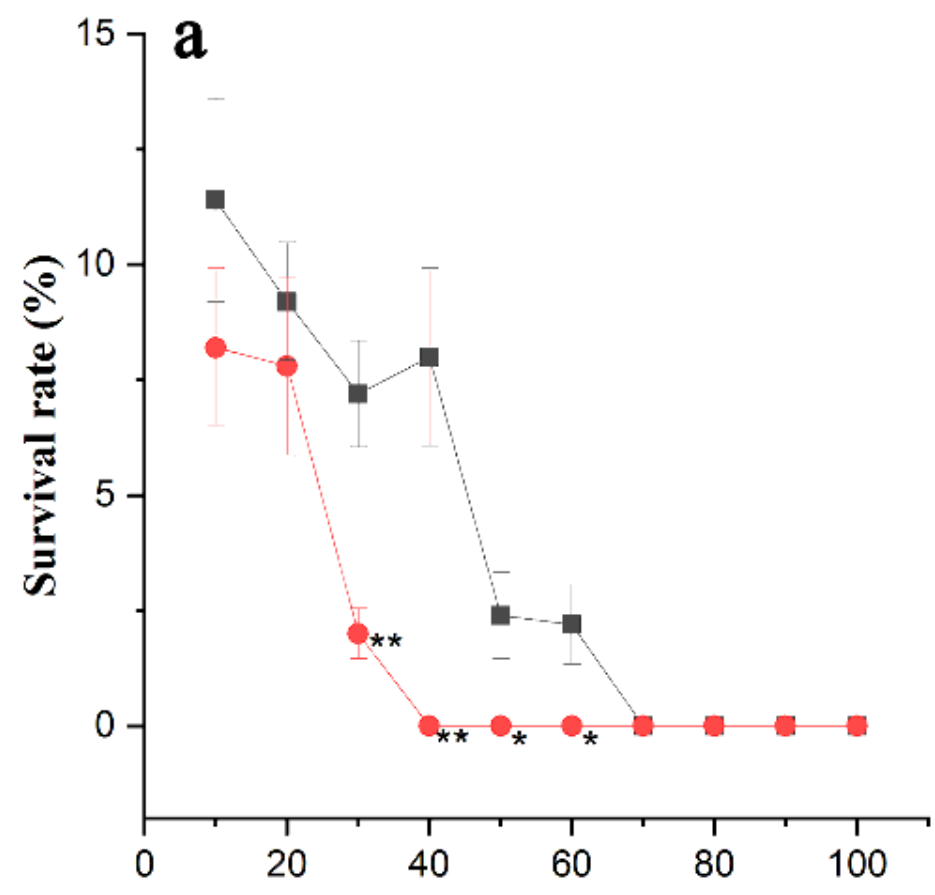

Exposure duration under field condition (d)

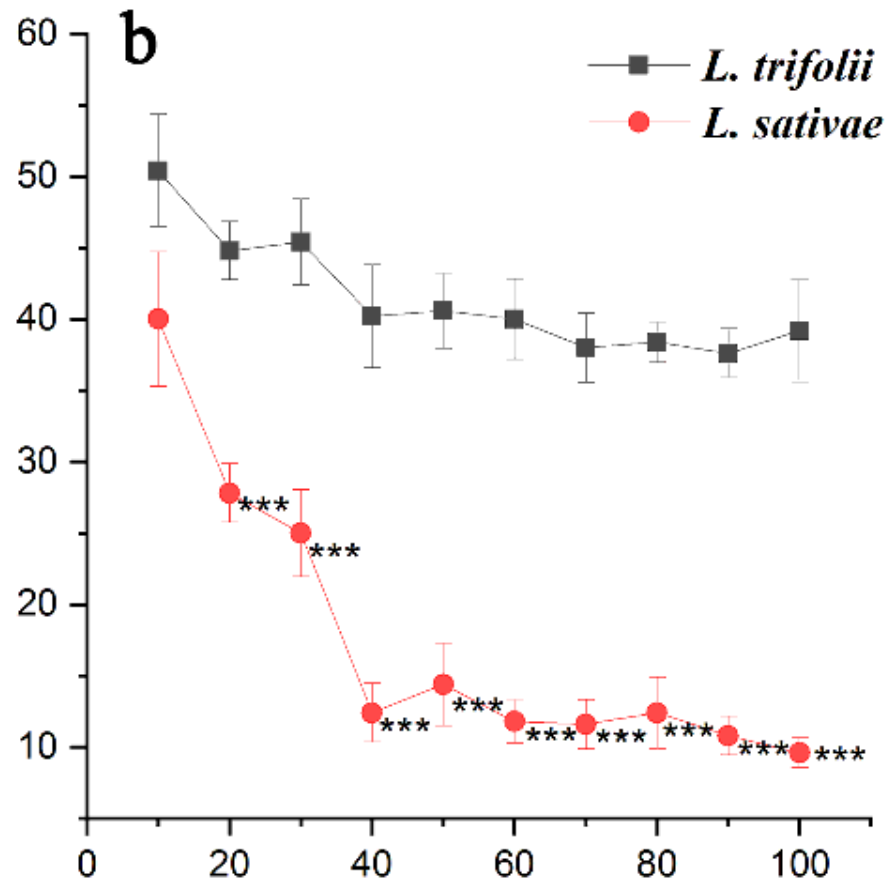

Exposure duration under greeenhouse condition (d)

\section{Figure 4}

Survival rate of the overwintering pupae of L. trifolii and L. sativae under field (a) and greenhouse (b) conditions at different exposure durations in northern China. ${ }^{\star} \mathrm{P}<0.05 ; * \star \mathrm{P}<0.01$; ${ }^{\star \star \star} \mathrm{P}<0.001$. Bars indicate mean \pm SEM 

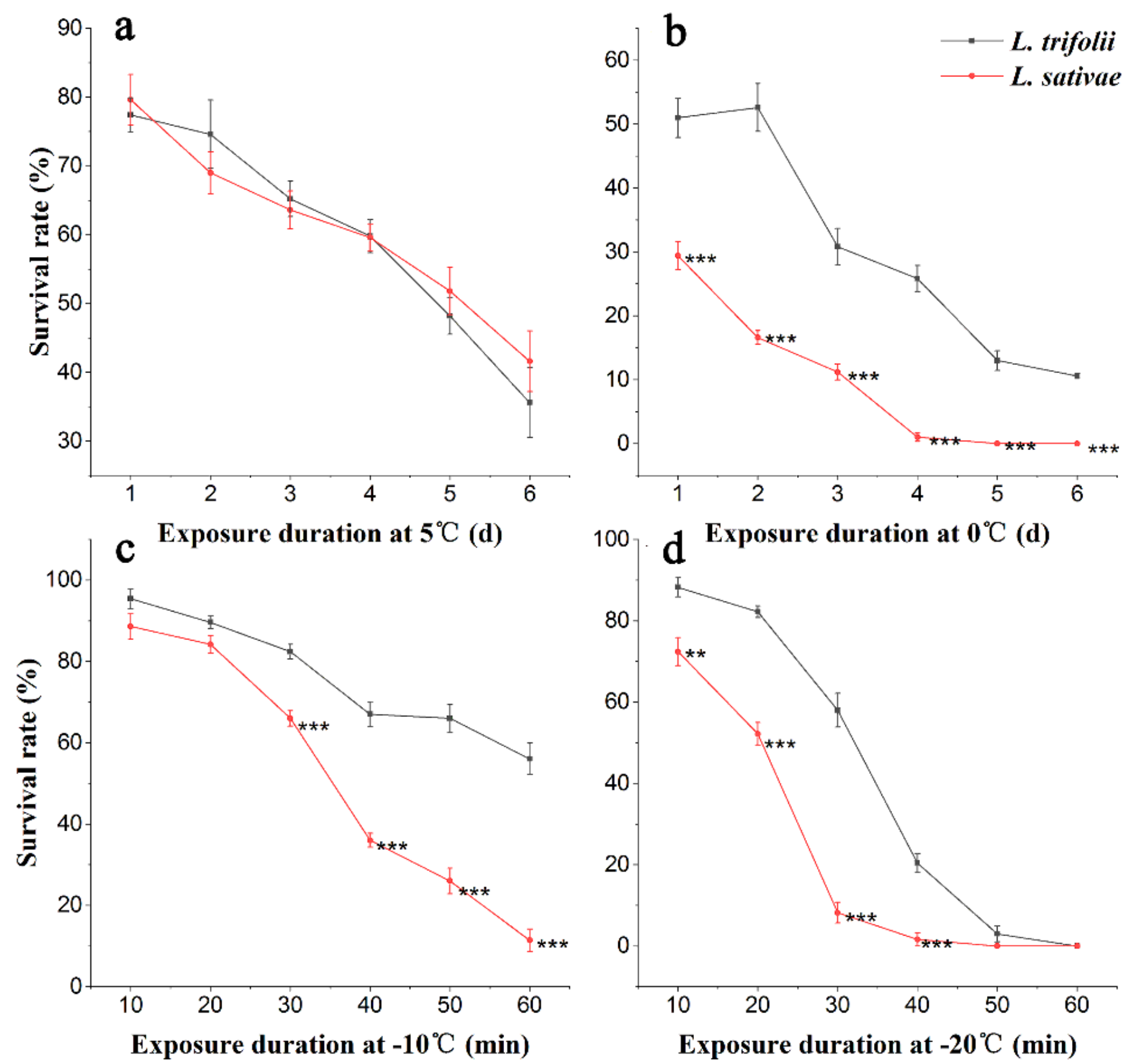

Figure 5

Survival rate of the pupae of L. trifolii and L. sativae at $5^{\circ} \mathrm{C}(\mathrm{a}), 0^{\circ} \mathrm{C}(\mathrm{b}),-10^{\circ} \mathrm{C}$ (c) and $-20^{\circ} \mathrm{C}(\mathrm{d})$ for different exposure durations. ${ }^{\star * *} \mathrm{P}<0.001$. Bars indicate mean $\pm \mathrm{SEM}$ 


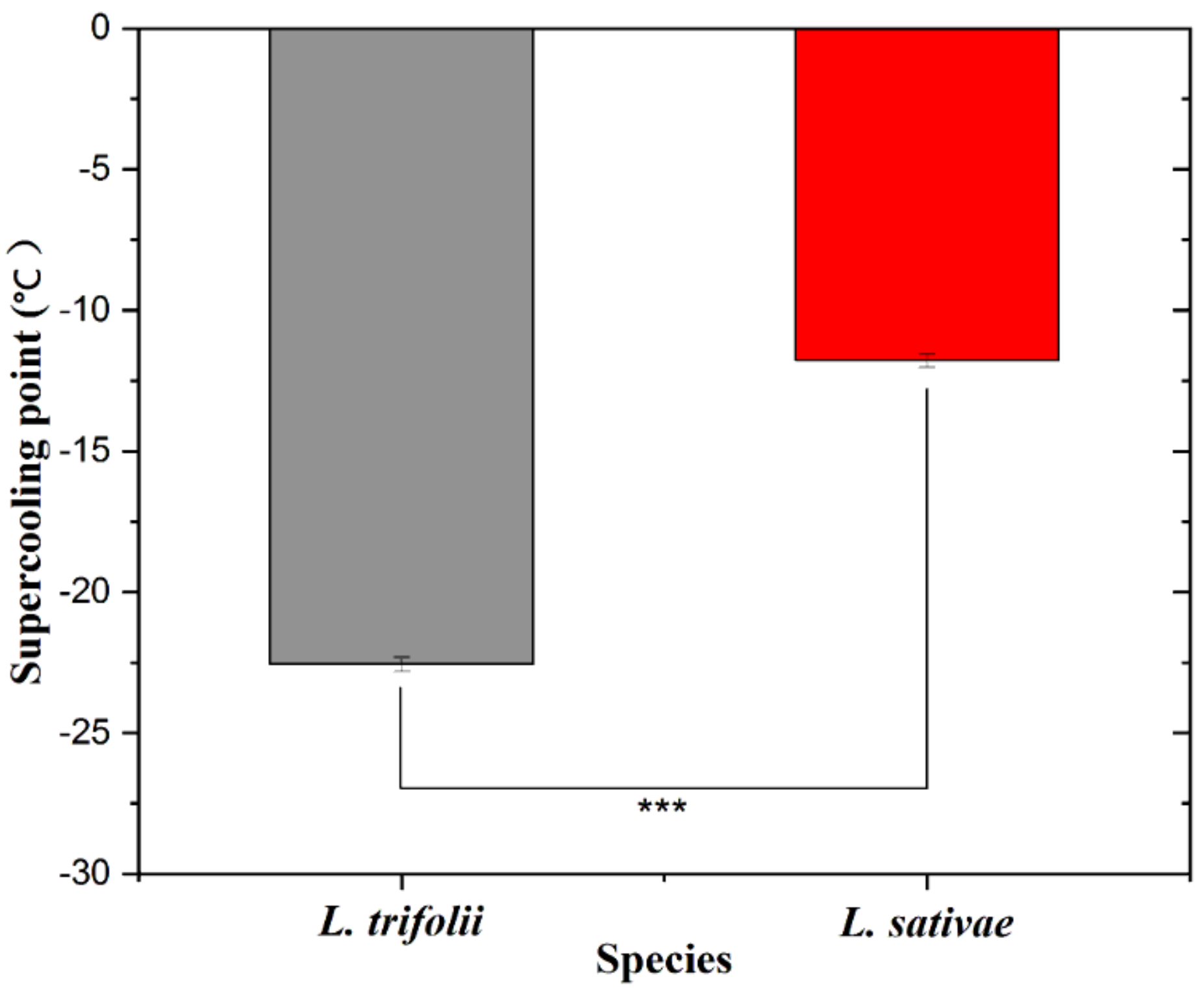

Figure 6

The supercooling point (SCP) of L. trifolii (dark bar) and L. sativae (red bar). ${ }^{\star \star \star} P<0.001$. Bars indicate mean \pm SEM 